\title{
Mm Waves Role in Satellite Communication
}

\author{
Dhruva Teja Jangam $^{1}$, V.Chaitanya Reddy ${ }^{2}$, T.S.R.Prasad ${ }^{3}$, T.Ravi $^{4}$ \\ ${ }^{1,2}$ Department Of Electronics \& Communication/ Kl University,India,A.P (Vij)). \\ ${ }^{3,4}$ (Assosiate Professor, Dept.Ece /Kl University,India,A.P(Vij))
}

\begin{abstract}
Millimeter Wave satellite communications are discussed with only modest site separation and switched diversity. Various aspects of MM Wave communication link at $35 \mathrm{GHz}, 60 \mathrm{GHz}$ and $94 \mathrm{Ghz}$ frequencies for satellite applications are discussed in the paper. Link calculations are carried out and possible hardware configurations are sketched out briefly in respect of Ground Satellite and Inter Satellite Communications Links
\end{abstract}

Key word: Satellite communication, Satellite Spacing, Millimeter wave communication

\section{Introduction}

The frequency band of Millimeter Wave (MM Wave) in Electromagnetic spectrum is $30-300 \mathrm{GHz}$ and is sometimes called the Extremely High Frequency (EHF) range. Apart from Radar system, communication system is another important application of MM Waves which proved better than Microwaves/optics in certain features. Certain characteristics of the earth's atmosphere pose both problems and solutions for millimeter wave applications. For example, at $60 \mathrm{GHz}(5 \mathrm{~mm}$ or 0.2 inches wavelength) oxygen molecules will interact with electromagnetic radiation and absorb the energy. This means $60 \mathrm{GHz}$ is not a good frequency for use in longrange radar or communications, because the oxygen absorbs the electromagnetic radiation - and the signal. On the other hand, since the $60 \mathrm{GHz}$ signal does not travel far before it loses all its energy, this frequency comes in handy for secure short-range communications, such as local wireless area networks used for portable computers, where it is important that hackers do not tap into the data stream. Another use for $60 \mathrm{GHz}$ technology is communications between satellites (called cross-linking) in high earth orbit. Since there is almost no oxygen in space at the geosynchronous altitudes of $43,000 \mathrm{~km}$ or 26,000 miles), $60 \mathrm{GHz}$ works just fine for communication between satellites

\section{Satellite Communication}

Satellite Communication in telecommunications by use of artificial satellites to provide communication links between various points on Earth. Satellite communications play a vital role in the global telecommunications system. Approximately 2,000 artificial satellites orbiting Earth relay analog and digital signals carrying voice, video, and data to and from one or many locations worldwide. A typical satellite link involves the transmission or uplinking of a signal from an Earth station to a satellite. The satellite then receives and amplifies the signal and retransmits it back to Earth, where it is received and reamplified by Earth stations and terminals. Satellite receivers on the ground include direct-to-home (DTH) satellite equipment, mobile reception equipment in aircraft, satellite telephones, and handheld devices. . Satellites located in this Geostationary Orbit are available to all Earth Stations within their shadow, 100\% of the time. The prime advantage of Satellite Communication over terrestrial communication is greatly exceeding coverage area. The maximum area that can be covered by a Geostationary Satellite is around $33 \%$ of the earth's surface. That means the communication needs of a country like India can be met by a Communication Satellite launched and located in the Geostationary Orbit.

The main disadvantage with Satellite Communication (Geostationary) is the time delay of around 260 milliseconds. In the case of continuous Television transmissions this factor does not matter. But in the case of control signals that move back and forth between a computer's CPU and its peripheral devices this factor is critical. Here, the computer systems that use Satellite Communication system should be carefully designed and realized to include/absorb this type of time delay.

The distance (d) between a particular location on the earth's surface and a Geostationary Satellite depends on Latitude $(\theta)$ and Longitude $(\Phi)$ of the location and longitude $(\Phi)$ of the satellite. This distance can be estimated in (i.e., (1) reads as "equation 1")

When both $\theta \& \Phi$ are equal to $0^{\circ}$, (i.e., on earth's equator) the Geostationary Satellite Orbit is at a height of around $35,800 \mathrm{Km}$. The maximum height is around $42,650 \mathrm{Km}$ when both $\theta \& \Phi$ are equal $90^{\circ}$.

The shadow of a Satellite includes all the Earth Stations that have a LOS (Line of Sight) path to the Satellite and within the Radiation Patterns of the Antennas located onboard the Satellites. These advantages of this 
application outweigh drawbacks like signal loss and time delay caused due to the great distance of satellite from earth.

Irrespective of the MM Wave band allocations for satellite links across the world, the estimations are carried out for various RF parameters.

\section{II.1 Mmwaves In Satellite Communications}

MM Wave Communication Satellites can be employed as repeaters. In this case, they receive signals in one frequency band (up link $36 \mathrm{GHz}$ or $96 \mathrm{GHz}$ or $62 \mathrm{GHz}$ ) and re-transmit the signals in another frequency band (down link $34 \mathrm{GHz}$ or $94 \mathrm{GHz}$ or $60 \mathrm{GHz}$ ) like a conventional transponder (Fig.5). These satellites can use $10 \mathrm{~W}$ Low Power Amplifiers at $34 \mathrm{GHz} / 36 \mathrm{GHz}$ or $94 \mathrm{GHz} / 96 \mathrm{GHz}$ or $60 \mathrm{GHz} / 62 \mathrm{GHz}$. The requirement of using Low Power of this order is to have optimal use / conservation of the solar energy available on- board the satellite. To compensate for the lower powers, the satellites employ higher gain/highly directional antennas and Low Noise Amplifier based receivers. The difference of about 1-2 GHz in the Down Link/Uplink frequency is to ensure that no signal interference takes place during the communication phase. Here also the communication links employ digital techniques.

A Ground Based Satellite Receiver sees a 'COLD' Noise Source (RF) when looking at Satellite and hence it is practically possible for the Satellite to give small amount of output power where as Ground Based/Earth Station Receiver still maintains a good Signal to Noise Ratio. Thus these Satellites which are used as means of relaying information results in the communication of different types (Telephone, Fax, Radio, TV, Data) and Navigation, Weather Broadcasting and Defense applications (Surveillance, Reconnaissance, Aircraft/Missile Detection, Guidance and Control).Space Loss (Path Loss) - Satcom: This parameter is indicated by $(4 \pi \mathrm{d} / \lambda)^{2}$ where $\lambda$ is wavelength of the MM Wave carrier signal and' $d$ ' is the distance between Geostationary Orbit and the Earth station. The value is nothing but $-[97+20 \log f+20 \log d]$ where ' $\mathrm{f}$ ' is the carrier frequency in $\mathrm{GHz}$ and $\mathrm{d}$ is distance in Miles.

\section{II.2 Satellite Spacing - Geostationary Orbit}

The Geo Orbit exists as a circle around the earth at a height of around 35,800 Km. A good number of Satellites can be placed anywhere in this orbit. Longitude is used to specify a particular location in this orbit, because the Latitude for all the Geo Satellites is $0^{\circ}$.

The number of Satellites that can be placed in this orbit is determined by the minimum spacing between the orbits. Again this minimum spacing value is limited/controlled by the capability of earth station receivers to distinguish signals from any two adjacent satellites. When these two satellites use two different down link frequencies these can be placed very close to earth other because there will be no RF signal interference.

But when once the two satellites employ same up/down link frequencies, to avoid and minimize the signal interference, they should be located with a spatial elevation difference of $4^{\circ}$. For Geo orbits this corresponds to a distance of about $2950 \mathrm{Km}$ between the two adjacent satellites.

For the uplink frequency of $36 \mathrm{GHz}$ for the transponder indicated in Fig.5 (a), the Power (RF) reaching the Receiver $\left(P_{R}\right)$ of the satellite transponder (Geostationary) is estimated in equation 2 . $\left(G_{R}=\right.$ Gain of $R x$ Antenna on Satellite)

With these values, the $P_{R}$ turns out to be $-81 \mathrm{dBm}$. This signal is amplified by the first stage LNA with a gain of around $30 \mathrm{~dB}$ which gives an RF Power output of $-51 \mathrm{dBm}$ to the receiver input. The signal of $36 \mathrm{GHz}$ is down converted to a frequency of $34 \mathrm{GHz}$.

This signal is fed to a high power amplifier, with $60 \mathrm{dBm}$ power output and subsequently to the Transmit Antenna of Transponder (Gain of $30 \mathrm{~dB}$ ). (Fig.5b) In turn, the power reaching Earth Station Receiver after Antenna with a gain of $50 \mathrm{~dB}$ turns out to be $-71 \mathrm{dBm}$. This will be again suitably amplified and brought down to an appropriate IF to get the received communication signals processed.

Because Inter Satellite Links do not face the problem of atmospheric attenuation, $94 \mathrm{GHz} / 60 \mathrm{GHz} / 36$ $\mathrm{GHz}$ carriers can be used keeping in view of the smaller size of the system components and less power requirement of the communication system. Fig.6 indicates simplex Inter Satellite Communication system at 94 $\mathrm{GHz} / 60 \mathrm{GHz} / 36 \mathrm{GHz}$. A typical calculation for the above mentioned system at $60 \mathrm{GHz}, 36 \mathrm{GHz}$ and $94 \mathrm{GHz}$ are carried out as given below

\section{Figures and Tables}

Equation 1

$\mathrm{d}^{2}=\mathrm{X}^{2}+\mathrm{R}^{2}-2 \mathrm{Rx} \operatorname{Cos} \theta \operatorname{Cos} \Phi$

Where $\mathrm{R}=6378 \mathrm{Km}$, earth's Radius

$\mathrm{X}=42178 \mathrm{Km}=$ The distance from centre of earth to satellite. 
Equation 2

$P_{R}=P_{t}+G_{t}-$ Space loss - Plumbing loss of Transmitter $\left(L_{T}\right)$

$+\mathrm{G}_{\mathrm{R}}$ - Plumbing Loss of Receiver $\left(\mathrm{L}_{\mathrm{R}}\right)$

In this case

$$
\begin{aligned}
\mathrm{P}_{\mathrm{t}} & =70 \mathrm{dBm} \\
\mathrm{G}_{\mathrm{t}} & =40 \mathrm{~dB} \\
\mathrm{G}_{\mathrm{R}} & =30 \mathrm{~dB} \\
\mathrm{~L}_{\mathrm{R}}=\mathrm{L}_{\mathrm{T}} & =3 \mathrm{~dB} \\
\mathrm{~S}_{\mathrm{L}} & =215 \mathrm{~dB}
\end{aligned}
$$

IV. Figures and Tables

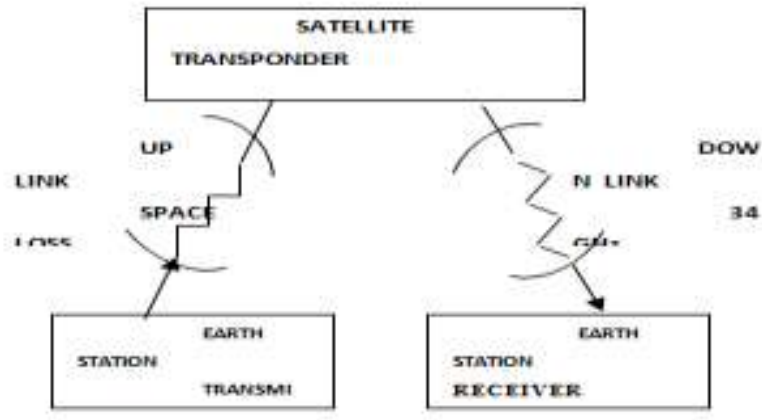

Sat Com Configuration Fig (5)

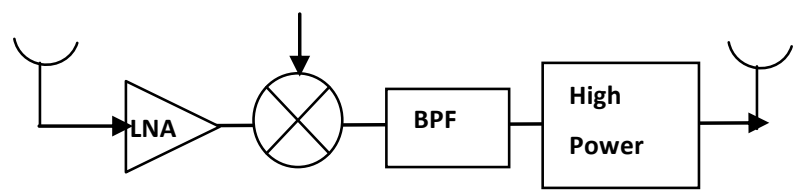

Satellite Transponder Fig (5.a)

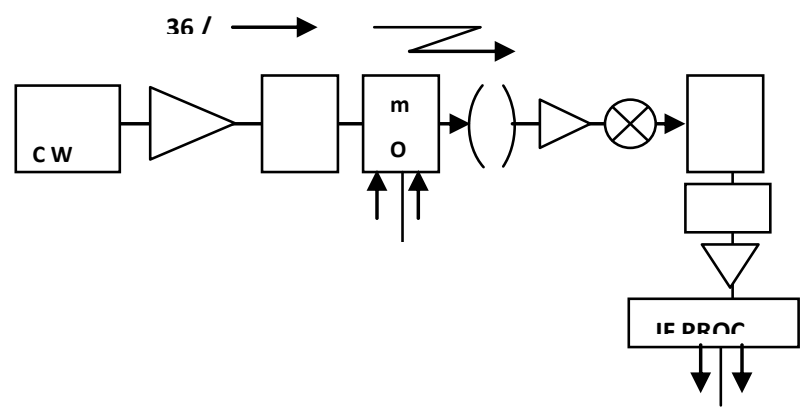

Inter Satellite Communication System Fig (5.b)

$\begin{array}{llll}\underline{\text { Parameter }} & \underline{6 G H z} & \underline{\underline{G H z}} & \\ \text { Inter Satellite Range } & 2,950 \mathrm{Km} & 2,950 & \underline{\underline{G H z}} \\ \left(\mathrm{~S}_{\mathrm{R}}\right) & & \mathrm{Km} & \mathrm{Km} \\ \text { Transmitter Power (Tx) } & 1.0 \mathrm{~W} & 100 & 10 \mathrm{~W} \\ & & \mathrm{~W} & \\ \text { Atmospheric Loss }\left(\mathrm{A}_{\mathrm{L}}\right) & 0 & 0 & 0 \\ \text { DataStream Capability } & 100- & 100- & 100- \\ & 1000 & 1000 & 1000 \\ \text { Transmitter Plumbing } & \mathrm{KBPS} & \mathrm{KBPS} & \mathrm{KBPS} \\ \text { Loss }\left(\mathrm{T}_{\mathrm{L}}\right) & 4 \mathrm{~dB} & 4 \mathrm{~dB} & 4 \mathrm{~dB}\end{array}$




$\begin{array}{llll}\text { Path Loss }\left(\mathrm{P}_{\mathrm{L}}\right) & 198 \mathrm{~dB} & \begin{array}{l}194 \\ \mathrm{~dB}\end{array} & \begin{array}{l}202 \\ \mathrm{~dB}\end{array} \\ \begin{array}{l}\text { Rx/Tx/Antenna Gain } \\ \text { Receiver Plumbing }\end{array} & 50 \mathrm{~dB} & 40 \mathrm{~dB} & 50 \mathrm{~dB} \\ \begin{array}{l}\text { Loss }\left(\mathrm{R}_{\mathrm{L}}\right) \\ \text { Power ReachingRx }\end{array} & 4 \mathrm{~dB} & 4 \mathrm{~dB} & 4 \mathrm{~dB} \\ \text { Input } & -76 \mathrm{dBm} & -72 & -70 \\ & & \mathrm{dBm} & \mathrm{dBm}\end{array}$

Fig (6)

\section{Conclusion}

At MM Waves, Communication links (Ground to Satellite and Inter Satellite) of different types can be realized.

\section{Acknowledgement}

I Wish to thank BSNL Rttc, Mysore staff for giving me a basic start on satellite communication and I acknowledges the support extended by Mr. .T. Ravi my collage guide.

\section{References}

[1] Gerard Maral "Satellite Communication System ",John Wiley \& Sons Ltd 2002.

[2] Paul Christopher, "Millimeter Waves for Broadband Satellite Communication, 75- 98

[3] GHz;" Proc. Ka and Broadband Conference, Isle of Ischia, Oct. 2003 